\title{
É FÁCIL TIRAR A CRIANÇA DA RUA, O DIFÍCIL É TIRAR A RUA DA CRIANÇA
}

\author{
Juliana Prates Santana \\ Thaís Mesquita Doninelli" \\ Raquel valente Frosi ${ }^{\#}$ \\ Sílvia Helena Koller"
}

\begin{abstract}
RESUMO. O presente estudo visa a descrever os principais objetivos de quatro instituições de atendimento a crianças em situação de rua segundo os seus coordenadores, assim como as concepções destes acerca da infância em situação de rua. Além disto, é investigada a percepção dos coordenadores sobre os objetivos dos jovens ao buscarem estas instituições e a relação que estes serviços estabelecem com a rua. Objetiva, ainda, descrever a avaliação que os coordenadores fazem do trabalho desenvolvido pelas suas instituições e pela rede especializada de serviços. Neste sentido, foram entrevistados seis coordenadores e vice-coordenadores de quatro instituições da cidade de Porto Alegre. Segundo os coordenadores, os objetivos institucionais são a reinserção social dos jovens atendidos, a defesa dos direitos dessa população, assim como o fornecimento das condições básicas de sobrevivência. Os coordenadores avaliam de forma positiva a forma de funcionamento em rede, apontando as principais dificuldades e os pontos a serem aprimorados.
\end{abstract}

Palavras-chave: instituições de atendimento, crianças e adolescentes em situação de rua, coordenadores institucionais.

\section{IT'S EASY TO TAKE THE CHILD OFF THE STREETS. IT'S HARD TO TAKE THE STREET OFF THE CHILD}

\begin{abstract}
The present study aimed to describe the main goals of four service centers for street children, according to their coordinators, as well as the coordinators ideas concerning childhood in the streets. Moreover, it aimed to investigate the perception of the coordinators about the youths' objectives for accessing these service centers and the relationship these services develop with the street context. This study aimed also to describe the evaluation these coordinators make of the work developed by their centers and by the network of services. Six institutional coordinators of four service settings of Porto Alegre were interviewed. According to the coordinators, the institutional objectives are the youths' social reengagement, the defense of the rights of such population, as well as supply basic survival conditions for them. The coordinators evaluated in a positive way the network functioning, and pointed out the main difficulties and the possible ways to improve it.
\end{abstract}

Key words: service institutions, street children and adolescents, institutional coordinators.

A literatura descreve as crianças e os adolescentes em situação de rua como jovens que utilizam o espaço da rua para obtenção de recursos para sua subsistência e/ou como local de moradia. Em sua maioria são jovens do sexo masculino, com idades entre doze e dezesseis anos, que estão ou já estiveram inseridos no

* Psicóloga, Mestre em Psicologia do Desenvolvimento, doutoranda em Estudos da Criança, na Universidade do Minho, Portugal. Membro do Centro de Estudos Psicológicos sobre Meninos e Meninas de Rua (CEP-RUA/UFRGS).

\# Acadêmica de Psicologia da Universidade Federal do Rio Grande do Sul. Membro do Centro de Estudos Psicológicos sobre Meninos e Meninas de Rua (CEP-RUA/UFRGS).

II Psicóloga, Doutora em Educação, pesquisadora do CNPq e docente do Programa de Pós-Graduação em Psicologia do Desenvolvimento da Universidade Federal do Rio Grande do Sul. Coordenadora do Centro de Estudos Psicológicos sobre Meninos e Meninas de Rua (CEP-RUA/UFRGS) 
contexto escolar (Forster, Barros, Tannhauser \& Tannhauser, 1992; Koller, 1994; Martins, 1996; Yunes, Arrieche \& Tavares, 1997). A saída destas crianças e adolescentes para a rua deve-se, na maioria das vezes, a questões financeiras e/ou à violência familiar (Aneci Rosa, Borba \& Ebrahim, 1992; Aptekar, 1996). No entanto, a literatura também indica que estes jovens, mesmo que esporadicamente mantêm contato com a família (Alves, 1998 e 2002; Santana, Doninelli, Frosi \& Koller, no prelo). Outras importantes características das crianças e adolescentes em situação de rua, constantemente mencionadas na literatura, são a utilização de substâncias psicoativas e os ganhos financeiros obtidos na rua decorrentes da mendicância e/ou trabalhos informais realizados (Maciel, Brito \& Camino, 1997). Por fim, as pesquisas ressaltam a frequiência em instituições e a participação em programas como importantes características desta população (Brito, 1999; Santana \& Koller, 2004).

As características das crianças e adolescentes em situação de rua apresentadas anteriormente influenciam a organização e a atuação das instituições de atendimento, consideradas como a principal forma de intervenção utilizada com esta população. Neste sentido, é de extrema importância que se investiguem as características destes locais, assim como as suas regras e normas de funcionamento, para que seja possível um aprimoramento constante destes serviços. É relevante, também, conhecer os coordenadores destes locais, suas concepções acerca da população atendida e a análise que fazem do serviço que desempenham. Afinal, estes profissionais são os responsáveis pelo tipo de atendimento que está sendo realizado, assim como são os maiores conhecedores da realidade institucional.

As características das instituições de atendimento a crianças e adolescentes em situação de rua sofreram modificações ao longo do tempo, em função das demandas políticas e sociais dos contextos nos quais estavam inseridas. Inicialmente, eram verdadeiros depósitos de crianças abandonadas. Passaram daí a locais de detenção e correção de "menores" infratores basicamente assistencialistas, apresentando funções que objetivavam a "salvação" e a "recuperação" destes jovens (Alvim \& Valladares, 1988). Desde 1990, as instituições estão sendo adequadas às configurações organizativas propostas pelo Estatuto da Criança e do Adolescente (Brasil, 1990). Isto significa tratar as crianças e os adolescentes atendidos como sujeitos de direitos e deveres, o que na prática implica uma série de mudanças, como, por exemplo, a garantia de acesso à educação formal, assim como o privilégio da permanência do jovem em uma família e comunidade.
Neste sentido, as instituições que se baseiem no ECA devem privilegiar a convivência familiar e comunitária em detrimento da institucionalização. Além disto, há uma tendência em organizar o atendimento a esta população em forma de uma rede integrada de serviços, visando a uma melhor qualificação e efetividade desses serviços. A reestruturação dos serviços, exigida pelo ECA, ainda não foi implementada na sua totalidade no país, mas importantes avanços têm sido verificados nos últimos anos. De qualquer forma, a rede deve ser um conjunto de sistemas e de pessoas significativas e identificadas como elos percebidos e compartilhados pelos indivíduos (Brito \& Koller, 1999).

$\mathrm{Na}$ cidade de Porto Alegre há uma tentativa de unificar os esforços governamentais e da sociedade civil organizada no atendimento das crianças e dos adolescentes em situação de rua. Com isto, a cidade possui uma rede integrada de serviços destinada a esta população, composta por uma escola, um acolhimento noturno, um serviço de saúde, um acolhimento diurno, um abrigo e diversos programas de intervenção social. Estas instituições e programas sociais fornecem alimentação, vestimentas, cuidados com a saúde e a higiene, além de propiciarem atividades educacionais, profissionalizantes e lúdicas. Esta rede especializada de serviços foi planejada para atuar conjuntamente com outras políticas sociais da cidade, buscando integrar o atendimento e efetivar a reinserção social desta população. O funcionamento em rede é apontado em outros estudos (Câmara, Medeiros, Ferriani \& Gomes, 2002; Câmara, Moraes, Medeiros \& Ferriani, 2000; Medeiros \& Ferriani, 1995) como ideal para o atendimento às crianças e aos adolescentes em situação de rua, pois possibilita o fornecimento de um serviço mais completo, que considera estes meninos e meninas em sua integralidade, respeitando, assim, os pressupostos estabelecidos pelo ECA (Brasil, 1990).

Ainda em relação às instituições de atendimento a crianças e adolescentes em situação de rua, é importante ressaltar o papel desempenhado pelos seus coordenadores, afinal são eles os principais definidores do perfil de atuação institucional. Isto foi verificado por Câmara e cols. (2000), que constataram ainda duas fontes motivacionais dos coordenadores em relação ao seu trabalho: a) a identificação com a criança, o trabalho e/ou a causa social; e b) a vertente missionária. Além disto, é importante considerar os discursos produzidos pelos funcionários, os quais balizam a sua prática. Segundo Luccinni (2000), estes discursos são, de forma geral, redutores, uma vez que caracterizam a criança em situação de rua unicamente em termos de vitimização ou de comportamentos 
delinqüentes. Câmara e cols. (2002) também abordam os discursos dos coordenadores institucionais, constatando que estes atribuem as seguintes características às crianças e os adolescentes atendidos: ausência de expectativas de vida, baixa auto-estima e condições familiares extremamente empobrecidas, com histórico de drogadição. Além disto, os coordenadores referem-se à violência como principal determinante da ida destes jovens para a situação de rua, ressaltando, contudo, que esta violência persiste no contexto da rua. É importante ressaltar que as concepções dos coordenadores acerca da população que atendem vão sendo alteradas ao longo do trabalho com estes jovens, inclusive como decorrência da freqüente participação destes coordenadores em movimentos sociais. Esta participação demonstra a identificação política e ideológica dos coordenadores com a problemática da infância em situação de risco.

Em função das questões anteriormente abordadas, o presente estudo visa a identificar os objetivos de quatro instituições de atendimento a crianças e adolescentes em situação de rua segundo os seus coordenadores, assim como descrever as concepções destes acerca da infância e da adolescência em situação de rua. Além disto, pretende identificar as demandas que, segundo os coordenadores, levam os jovens a buscar as instituições. Objetiva, ainda, descrever a relação estabelecida entre as instituições e a rua, assim como a avaliação feita pelos coordenadores sobre o trabalho desenvolvido pelas instituições que coordenam e pela rede especializada de serviços.

\section{MÉTODO}

\section{Participantes}

Participaram deste estudo quatro coordenadores e dois vice-coordenadores de quatro instituições de atendimento a crianças e a adolescentes em situação de rua, localizadas na cidade de Porto Alegre. Estas instituições são uma escola, um serviço de saúde, um albergue noturno e um alojamento diurno, e compõem, juntamente com outros programas e instituições, a rede municipal de atendimento a crianças em situação de rua da cidade. Tais instituições foram selecionadas dentre todas que compõem a rede de atendimento, por serem as mais citadas pelos jovens em situação de rua em um estudo prévio realizado na cidade de Porto Alegre que investigava a relação destes jovens com as instituições de atendimento (Santana, 2003). É importante esclarecer que estes seis profissionais formam a coordenação destes locais, sendo que a escola e o albergue noturno possuem coordenadores e vice-coordenadores, enquanto o serviço de saúde e o alojamento diurno possuem exclusivamente coordenadores. As instituições coordenadas por estes profissionais atendem unicamente a crianças e a adolescentes em situação de rua, e a faixa etária atendida vai dos sete aos dezoito anos incompletos. As instituições listadas, com exceção do alojamento diurno, são governamentais e possuem como objetivo comum a reinserção social da criança e do adolescente em situação de rua. Uma análise pormenorizada dos objetivos destas instituições a partir dos documentos institucionais, assim como uma descrição das mesmas instituições, foi realizada por Santana, Doninelli, Frosi e Koller (2004).

\section{Instrumento}

Foi utilizada uma entrevista semi-estruturada, construída a partir dos resultados obtidos em estudos anteriores realizados com estas instituições e com os jovens atendidos (Santana, 2003; Santana, Doninelli, Frosi \& Koller, no prelo). A entrevista se compõe de duas partes, a primeira das quais consta de cinco questões e visa à identificação dos participantes em relação à idade, sexo, formação acadêmica e experiência anterior de trabalho com crianças e adolescentes em situação de rua. A segunda parte da entrevista possui quatorze questões que abordam especificamente os objetivos deste estudo, anteriormente descritos.

\section{Procedimentos}

Os coordenadores das instituições foram convidados a participar do estudo, cujos objetivos lhes foram explicados. Após a assinatura do consentimento livre e esclarecido, realizou-se a entrevista, que foi gravada com a anuência do respondente e realizada de acordo com sua disponibilidade. Cada participante foi entrevistado individualmente dentro da instituição, em local escolhido por ele. Em geral, estes encontros foram permeados por interrupções decorrentes da própria atividade institucional. Tais momentos não prejudicaram a qualidade da entrevista, sendo, ao contrário, outra possibilidade de os pesquisadores conhecerem o contexto de investigação. A duração média das entrevistas foi de quarenta e cinco minutos, e elas foram transcritas para posterior análise.

É importante ressaltar que durante a realização deste estudo procurou-se seguir alguns procedimentos sugeridos pela Abordagem Ecológica do Desenvolvimento Humano - AEDH, (Bronfenbrenner, 1996; Bronfenbrenner \& Morris, 1998), os quais incluem a inserção ecológica dos pesquisadores no 
contexto de pesquisa (Cecconello \& Koller, 2003). Tal inserção incluiu a presença dos pesquisadores nas instituições durante a realização de atividades diversas e conversas informais com os participantes e outros integrantes das instituições. Segundo a AEDH, a inserção do pesquisador contribui para uma maior contextualização e validade ecológica dos dados e enriquece a pesquisa realizada. Além disto, a AEDH permite aos pesquisadores um entendimento que contempla os diversos espaços relacionados com a instituição (rua, família, rede de atendimento municipal, etc.).

\section{RESULTADOS E DISCUSSÃO}

Os dados do presente estudo foram submetidos à análise de conteúdo (Bardin, 1979). Os resultados serão ilustrados com as falas dos coordenadores, como forma de favorecer sua compreensão.

Em relação aos dados biossociodemográficos dos participantes, abordados na primeira parte da entrevista, cinco são do sexo feminino e um do sexo masculino, cujas idades variam entre 29 e 47 anos. Todos os participantes possuem formação universitária em diferentes cursos, havendo dois profissionais com pós-graduação. O tempo de trabalho com crianças e adolescentes em situação de rua varia de três a dezessete anos. Alguns participantes relatam, ainda, ter experiência com a população em situação de risco em geral.

Os conteúdos abordados na segunda parte da entrevista foram divididos em cinco grandes eixos temáticos, que serão apresentadas separadamente. Estes são: a) concepções dos coordenadores acerca da infância e da adolescência em situação de rua; b) objetivos institucionais segundo os coordenadores; c) percepção dos coordenadores acerca dos objetivos que levam os jovens a buscar as instituições; d) relação estabelecida entre a instituição e a rua; e, e) avaliação do trabalho institucional e da rede especializada de serviços.

\section{Concepções dos coordenadores acerca da infância e da adolescência em situação de rua}

O primeiro ponto a ser analisado é a concepção de criança e adolescente em situação de rua apresentada pelos participantes deste estudo. Segundo Nunes (1994), a análise destas concepções é de extrema importância, uma vez que influencia a forma como os coordenadores interagem com a população atendida. Em geral, os participantes ressaltam as violações de direitos a que estes jovens estão submetidos, tratando- se, por isto, de sujeitos em situação peculiar de desenvolvimento. Esta descrição assemelha-se à encontrada por Câmara e cols. (2002) ao pesquisarem a percepção dos coordenadores de programas de atenção às crianças e adolescentes em situação de rua acerca destes meninos e meninas.

Entre os vários aspectos mencionados pelos participantes, há um ponto que merece consideração especial. Trata-se de considerar ou não as crianças e adolescentes em situação de rua como iguais aos jovens da mesma faixa etária que não possuem esta história de vida na rua. Por um lado,Igualar estas populações significa não discriminar nem estigmatizar a população de rua, por outro lado, assumir esta igualdade pode ofuscar as peculiaridades dos grupos. É importante entender que, se existem diferenças, estas devem ser apontadas e compreendidas, inclusive para que o serviço se ajuste às demandas destes meninos e meninas.

É importante ressaltar a influência que o ECA (Brasil, 1990) exerce sobre as concepções acerca das crianças e adolescentes em situação de rua. A constante referência, por parte dos participantes, aos direitos destes jovens demonstra a incorporação de relevantes conceitos desse Estatuto. Tal incorporação pode ser considerada extremamente positiva, uma vez que o ECA é apontado por todos como um grande avanço conceitual, jurídico e, até mesmo, ético a respeito da juventude. Um discurso acerca das crianças e dos adolescentes em situação de rua que fosse baseado no ECA seria, em princípio, contrário aos discursos redutores descritos por Luccinni (2000). Para ele, a intervenção proposta para as crianças e adolescentes em situação de rua baseia-se, em geral, em um discurso institucional conformista, adaptado à imagem da criança da rua predominante na opinião pública nacional e internacional, assim como na administração e no mundo da política. Alguns discursos concebem as crianças exclusivamente como vítimas, enquanto a realidade delas é extremamente multifacetada. Tais discursos redutores, muitas vezes, impregnam as instituições de forma prejudicial. Ao falarem sobre os jovens em situação de rua com base no ECA, seria possível a construção de um discurso mais plural. Não porque o ECA os mencione diretamente, mas porque baseia a intervenção em múltiplos aspectos da sua realidade de vida.

Em geral os participantes afirmam que as suas concepções de infância e adolescência em situação de rua alteraram-se ao longo do trabalho com esta população:

"Quando a gente não tá trabalhando diretamente, a gente passa pelas ruas e vê, 
né? Então é um olhar muito de fora. Ah, são pivetes, são trombadinha. Depois quando a gente entra, começa o trabalho, começa a entender todas as relações, por que estas crianças tão na rua, né?"

Isto demonstra a necessidade da constante discussão dentro dos serviços sobre as concepções de cada integrante da equipe acerca do público atendido. $\mathrm{O}$ acompanhamento daqueles que chegam ao serviço deve ser cuidadosamente pensado pela equipe, para poderem os novos integrantes refletir acerca das suas concepções, antecipando questionamentos que irão decorrer da sua prática.

\section{Objetivos institucionais segundo os coordenadores}

Cinco participantes citam como objetivo institucional a reinserção social dos jovens. Esta ocorreria a partir do retorno à família de origem ou substituta; do retorno à comunidade, incluindo o reingresso nas escolas regulares; do ingresso em abrigos; e da própria preparação dos meninos para a geração de renda autônoma. Um participante diz que

\footnotetext{
"quando estas possibilidades de reinserção social são inviáveis uma alternativa é a permanência na própria rede de atendimento para crianças e adolescentes em situação de rua".
}

Esta é uma saída questionável, pois cristaliza a situação de rua em que o jovem se encontra, mantendo-o com o estigma de pertencer a essa população.

Outro objetivo institucional apontado é o papel de defensor dos direitos desta população junto ao poder público e à sociedade civil. Neste sentido, um participante afirma que o principal papel da instituição é dar visibilidade a esta população, uma vez que a existência deste local tornaria pública e notória a realidade destes adolescentes:

\footnotetext{
"Acredito que o grande mérito da existência 'da instituição' é dar visibilidade. E é, em um certo sentido, dar existência no social para esta realidade, pra eles."
}

Esta é uma questão extremamente delicada, pois é tênue a linha divisória entre dar visibilidade e "manter longe dos olhos" da sociedade este problema social. O próprio participante reconhece este risco, mas afirma que cabe aos serviços buscar alternativas que impliquem a sociedade nesta problematização.
A defesa dos direitos da população em situação de rua também ocorre, de acordo com os participantes, a partir do "tensionamento" das políticas públicas existentes. Este "tensionamento" demonstra que as instituições pretendem construir as condições necessárias ao retorno à comunidade por parte dessa população. Demonstra também uma idéia de prevenção, pois intervir neste contexto poderia vir a impedir que outras crianças saíssem de suas comunidades, repetindo o processo de ida às ruas.

Alguns entrevistados apontaram que estes jovens vivem, muitas vezes, em condições subumanas, sendo por isto um dos objetivos da instituição humanizá-los, reinseri-los em um processo que pode ser inclusive considerado civilizatório:

"O objetivo (institucional) é que a gente tenha condições de humanizar dezenas de jovens que estão vivendo na rua, sem nenhum tipo de cuidado sem nenhum tipo de olhar."

Esta idéia de humanização é extremamente inquietante, pois aceitá-la significa concordar com a hipótese de que estas crianças e adolescentes já não possuíam características suficientes para serem enquadrdos na categoria de humanos, e isto se confrontaria com a idéia de que estes jovens são pessoas em desenvolvimento e sujeitos de direitos e deveres (conforme eles próprios mencionaram anteriormente). Contudo, não é possível descartar tal afirmação, uma vez que esta pode ter importantes desdobramentos. Por um lado, trata-se de uma grave denúncia acerca da situação em que vivem estes jovens, situação que coloca as instituições como locais que tentam revertê-la através dos seus serviços. Outra possibilidade é que tal afirmação seja realmente uma contradição no discurso institucional, e justamente por isto represente tão ricamente a realidade destes locais. Será que uma das principais dificuldades institucionais não é precisamente defender os direitos e os deveres de sujeitos que nem sequer receberam o status de humanos? Neste sentido, humanizar representa o primeiro passo para que qualquer tipo de trabalho possa ser efetivado com esta população de crianças e adolescentes em situação de rua.

Um importante objetivo institucional apontado é o fornecimento das condições básicas de sobrevivência. Também é mencionado o resgate da auto-estima, através dos cuidados com a saúde física e mental. Em geral, estes objetivos aparecem como pontos iniciais para o desenvolvimento do trabalho como um todo, visto que possibilitam a criação de vínculos 
imprescindíveis para a realização de trabalho institucional.

Ao serem questionados sobre como operacionalizam seus objetivos, os participantes descrevem procedimentos semelhantes em todas as diferentes instituições. Tais rotinas consistem primeiramente no acolhimento do jovem, a partir da investigação da história de vida através do diálogo com o adolescente e dos seus registros junto à rede. A seguir, as instituições realizam as atividades quotidianas propostas, tais como prática de aulas, oficinas, jogos, entre outras. Concomitantemente a isto, são realizadas reuniões de equipe objetivando monitorar a permanência do adolescente na rede de atendimento. A operacionalização da última etapa do trabalho, que é justamente a maneira como se realiza a reinserção objetivada, é descrita a partir do funcionamento da rede de serviços municipais destinados a estes meninos e meninas em situação de rua.

Segundo os participantes, a reinserção é objetivo da própria instituição, mas sua execução ocorre em um espaço ampliado de discussão que constitui justamente a referida rede de atendimento; ou seja, cada instituição possui particularmente o objetivo da reinserção, mas nenhuma delas o operacionaliza sem referir-se à rede de atendimento. Isto pode demonstrar a eficiência desta forma de funcionamento, mas também pode ser uma simples transferência de responsabilidades. Apenas um estudo específico desta rede, de sua estrutura e função, de sua dinâmica de relacionamento e formas de comunicação, possibilitaria uma melhor compreensão desta questão.

\section{Percepção dos coordenadores acerca dos objetivos que levam os adolescentes a buscar as instituições}

Quando perguntados sobre o que leva os adolescentes a buscar as instituições, os participantes citam a garantia de sobrevivência e a busca de proteção. Afirmam que, se os adolescentes fossem perguntados acerca dos objetivos institucionais, descreveriam as atividades desenvolvidas nas instituições, e reconheceriam o papel de cuidadores que a instituição e seus integrantes desempenham em suas vidas. Acreditam que o objetivo de reinserção não é pretendido pelos jovens, reconhecendo que caberia à instituição torná-lo mais claro ao longo do trabalho desenvolvido no serviço. Contudo, não é possível verificar, a partir da fala dos participantes, como esta construção ocorreria, visto que não são previstas atividades com este fim.

Além de acreditarem que estes jovens não procuram as instituições em função da reinserção proposta, dois participantes afirmam que verbalizar este objetivo institucional para os adolescentes poderia amedrontá-los, fazendo com que eles, inclusive, interrompessem a freqüência aos serviços:

"Acho que eles não fazem grandes elucubrações. 'Ah, eu ficando aqui, daqui a pouco eu vou ir pro abrigo'. Não, pelo contrário. Isto, aliás, nem é verbalizado pra ele também, porque isto assusta. 'Eu voltar pra família ou eu vou voltar pra instituição' isto assusta."

Percebe-se a dificuldade em construir no jovem o objetivo de reinserção almejado pela instituição, o que seria imprescindível para efetivar o trabalho institucional. Ao contrário, verifica-se que os objetivos das instituições é que vão se moldando aos objetivos dos jovens, inversamente do que seria pretendido.

Apenas um participante afirma que os adolescentes buscam a instituição visando à profissionalização, que pode ser entendida como uma forma de reinserção. Santana (2003) verificou que a busca pela profissionalização ocorre em torno dos dezesseis anos, quando se inicia uma preocupação com a inserção no mercado de trabalho.

\section{A relação estabelecida entre a instituição e a rua}

A relação estabelecida entre a instituição e a rua ocorre, segundo os coordenadores entrevistados, através de um integrante do serviço que compõe a equipe de educadores de rua da rede municipal de atendimento. No entanto, é necessário questionar até que ponto esta forma de funcionamento consegue integrar todos os membros da equipe com a situação de rua. Seria importante que todos os funcionários pudessem interagir com as crianças e os adolescentes no espaço da rua, visto que esta seria uma excelente forma de aproximação com a realidade destes jovens.

A mencionada relação entre a instituição e a rua estreita-se através dos jovens atendidos, uma vez que estes possuem em comum uma história de vivência na rua. Trata-se de uma relação tensa, que pode ser ilustrada pela fala de um respondente:

"Eu diria que estabelece uma relação muito direta e até em alguns momentos uma relação muito desprotegida, porque a rua é logo ali, né? Então, a rua nos invade em determinados momentos. A rua entra. Então, a relação com a rua é uma relação muito visceral. Uma relação com muita proximidade e, às vezes, a gente se ressente um pouco, quando se dá conta do quanto a gente está desprotegido, desamparado, numa situação de violência. 
(...) Quer dizer, neste sentido é uma relação muito visceral, a rua invade o serviço, entra por todos os poros".

Esta tensão mencionada pelo participante se concretiza na dificuldade da instituição em romper a relação do jovem com a rua, uma vez que tal relação interfere na efetividade do trabalho proposto por esses serviços:

"Eu vejo como maior desafio é a gente poder minimamente fazer com que esta gurizada rompa esta relação com a rua. Com o espaço da rua como seu espaço de sobrevivência."

Este problema é agravado em função de a própria instituição considerar a rua muito atraente, temendo, por isto, propor ao adolescente o abandono do contexto da rua. Parece que a instituição parte do princípio de que a "disputa" entre a rua e o serviço que ela oferece está perdida desde o início, e isto evidencia-se na frase: "É fácil tirar o menino da rua. $O$ difícil é tirar a rua do menino."

Conforme constatado pelas pesquisadoras, a atratividade da rua leva a uma busca da instituição por assemelhar-se com este ambiente, sendo um desafio institucional saber os limites desta aproximação. A instituição percebe-se na contingência de possuir um número suficiente de características similares às da rua, com o objetivo de atrair a criança e o adolescente. Ao mesmo tempo, deve se diferenciar para não ser apenas mais uma forma de manter o jovem na rua, já que esta é justamente a situação que pretende alterar. Desta forma, a relação da instituição com a rua deve estar em um ponto intermediário entre a proximidade e a distância.

A rua deveria ser, segundo um respondente, tema de discussão constante com os jovens dentro das instituições, para que desta forma estes pudessem transformar os significados que atribuem à rua, passando a encará-la como espaço apenas de transição. Outro participante complementa que nestas discussões os funcionários não devem fazer julgamentos morais sobre o adolescente estar na rua, já que estes funcionariam como uma barreira entre os jovens e os funcionários.

\section{Avaliação do trabalho institucional e da rede especializada de serviços}

A avaliação dos resultados obtidos por uma instituição deve ser uma constante prática interna, sendo esta a principal forma de qualificar os serviços prestados e dimensionar o seu impacto social. Isto é de extrema importância, principalmente quando se refere a instituições que são responsáveis, enquanto agentes de políticas públicas, por responder a uma demanda social. Em relação a estas avaliações que ocorrem nas instituições, foi possível constatar que elas se centram na prática quotidiana, havendo dificuldades em avaliar o trabalho como um todo. É importante apontar que este não é um problema enfrentado apenas por estas instituições, havendo uma dificuldade geral na avaliação de programas e projetos sociais (Bandeira, 1999).

Os coordenadores avaliaram o trabalho que realizam nas instituições a partir das seguintes questões: a) papel de tais instituições na vida dos jovens em situação de rua; b) alcance dos objetivos inicialmente propostos; c) dificuldades e gratificações dos seus trabalhos; e, d) vantagens e desvantagens do trabalho em rede.

Em relação ao papel das instituições na vida dos jovens em situação de rua, os participantes afirmam que estes locais garantem a sobrevivência destas crianças e adolescentes, sendo comparados, pelos coordenadores, às próprias casas deles. As instituições também são entendidas como espaços privilegiados de acolhimento, onde os adolescentes são ouvidos e respeitados, havendo, em relação a eles, uma aceitação incondicional. A falta destas características nas instituições que prestavam atendimento a estes jovens antes da sua ida para a rua é apontada como a causa principal do seu fracasso.

Alguns coordenadores não conseguem avaliar o alcance do trabalho desenvolvido nas instituições na vida dos jovens atendidos. Isto demonstra a necessidade de estudos que consigam avaliar o impacto destes programas no desenvolvimento destes jovens, como forma de aprimoramento do trabalho realizado.

Quando avaliam o alcance de objetivos institucionais, os coordenadores reconhecem a dificuldade em propiciar a reinserção social ao conjunto dos jovens atendidos, que é justamente o objetivo final destas instituições. Apesar deste reconhecimento, segundo afirmam todos os participantes, as instituições alcançam parcialmente os objetivos propostos, sendo que, em alguns casos, esta avaliação é dificultada pelo curto tempo de existência dos serviços. A avaliação positiva feita pelos participantes enfoca conquistas quotidianas, que podem ser consideradas pequenas em relação aos objetivos propostos, mas possibilitam à equipe suportar o elevado nível de frustração presente neste tipo de trabalho. Entre estas pequenas conquistas destacam-se os poucos casos em que os jovens atendidos retornaram à comunidade. Um participante 
aponta a própria continuidade do serviço como um resultado positivo:

“... é uma vitória a gente ter sobrevivido, eu falo que é uma vitória a gente ter sobrevivido e continuarmos com ímpeto, continuarmos acreditando que a proposta é possível de ser levada a termo."

Por outro lado, os participantes reconhecem pontos que precisam ser aprimorados. Os fracassos são atribuídos, em geral, à própria situação de rua em que o jovem se encontra e à continuidade das estruturas sociais geradoras de tal situação. Um participante afirma que a instituição cumpre o papel a ela atribuído, mas a reinserção não é alcançada por causa da deficiência dos serviços na própria comunidade. Isto remete a um ponto delicado, que é o fato de o serviço específico a crianças e adolescentes em situação de rua ser muito mais individualizado do que os serviços destinados a jovens que não possuem história de rua. Isto poderia ser um dos motivos que justificaria a não-reinserção social destes jovens em suas comunidades de origem. Esta idéia pode ser exemplificada na frase de um participante:

\footnotetext{
"Depois como é que eles vão querer ir embora daqui? É, é uma contradição. (...) É o fio da navalha que a gente caminha, né? De não ser tão maravilhosos como a ilha da fantasia, que aí eles nunca vão querer ir embora. E é o que eles dizem pra gente: 'Mas eu não quero ir embora daqui. Onde é que eu vou achar outra 'instituição' que nem essa?' Então é meio perigosa a nossa existência, né?".
}

Em relação às dificuldades encontradas no trabalho institucional, um participante menciona as complicações surgidas quando o adolescente completa dezoito anos, uma vez que são escassas as políticas públicas de atendimento a esta faixa etária, provocando um rompimento abrupto no trabalho que vinha sendo desenvolvido. As limitações inerentes aos serviços públicos também são mencionadas como dificuldades enfrentadas pela instituição. Os participantes referem-se, ainda, à dificuldade em manter uma reciclagem profissional constante, que consiga atender às demandas existentes através da busca de novas alternativas e metodologias de trabalho. Esta questão está relacionada também com a manutenção da motivação da equipe em continuar desempenhando este serviço, uma vez que aprender a lidar com a própria impotência parece ser outro grande desafio do trabalho:

"Eu acho que a grande dificuldade é a gente, vamos dizer assim, se educar para saber comemorar pequenos passos. (...) A grande dificuldade é a gente sair do lugar da onipotência e não cair no lugar da impotência."

Por fim, um participante aponta o uso de substância psicoativa pelos adolescentes como um das maiores concorrentes institucionais:

"O grande impedimento é realmente a droga, né? Que a gente, eu sempre digo assim, que é frustrante, porque sempre que a gente compete a gente perde, né? (...) Ser mais interessante, ser mais atrativo que a droga é o grande desafio."

Em relação às gratificações obtidas a partir do trabalho nas instituições, foi possível identificar uma ampla variedade nas respostas. Um dos tipos de resposta encontrados refere-se às modificações observadas no comportamento dos adolescentes atendidos, assim como aos casos em que os retornos à comunidade, à família ou à escola foram bemsucedidos. Incluem-se também neste tipo de resposta, idéias que demonstram a gratificação decorrente da integridade física destes jovens, uma vez que estão expostos a muitos riscos no contexto da rua: "É olhar a cara deles todo dia, ver que eles estão aqui, tão vivos, tão inteiros ..."

Os participantes também consideram gratificante os adolescentes demonstrarem pertencimento à instituição, reconhecendo estes locais como espaço de proteção. Outras gratificações salientadas são os ganhos pessoais dos participantes provenientes do trabalho nestes locais:

"Gratificações? Bom. Pessoalmente, eu acho assim, que quem entra pra trabalhar aqui jamais sairá daqui igual ao que era. A gente cresce muito enquanto pessoa, né? Na nossa relação familiar, nossa vida fora daqui".

Os coordenadores enfatizam ainda como gratificante perceberem que os adolescentes os diferenciam dos outros adultos de sua história: "Não somos aqueles adultos que eu diria, os adultos abusivos, mas adultos que estão sendo parceiros".

As demonstrações de carinho dos adolescentes para com os coordenadores são citadas como importantes gratificações do trabalho, uma vez que 
demonstram o fortalecimento dos vínculos considerados tão importantes para o desenvolvimento dos mesmos adolescentes. Além disto, uma equipe de trabalho qualificada e integrada é uma importante fonte de satisfação para os coordenadores, uma vez que o processo de formação de tal equipe é extremamente árduo e trabalhoso.

O funcionamento em rede é positivamente avaliado pelos entrevistados que apontam os benefícios desta estrutura, pois os encargos das instituições são reduzidos, permitindo a cada serviço alocar sua atenção nas atividades que respondem aos seus objetivos específicos. Uma vez que a instituição passa a desempenhar tarefas mais específicas, a identidade institucional pode ser fortalecida tanto para os integrantes das equipes como para os jovens atendidos. Além disto, trabalhar em rede significa, para os participantes, a possibilidade de monitoramento das crianças e dos adolescentes que "circulam" pelos serviços. Outro aspecto relativo à estruturação dos serviços em rede é o fato de ser uma forma de atuação relativamente recente, cuja qualificação deve ser construída a partir da sua experiência:

\footnotetext{
"Porque discute, diverge em cima do erro, em cima do acerto, vamos vendo como é que vai. Então é um trabalho novo trabalhar em rede, né? Então a gente está aprendendo ainda, e temos várias lacunas."
}

Não obstante, também são apontadas dificuldades inerentes a esta estrutura e relacionadas à falta de comunicação e a diferenças das dinâmicas de trabalho, entre outras. É importante enfatizar que o funcionamento em rede é justamente uma resposta às constantes críticas de que o trabalho com jovens em situação de rua não era efetivo em função de desarticulação dos serviços existentes. Câmara e cols. (2002) afirmam que a atuação isolada das instituições é, segundo os seus coordenadores, um dos grandes problemas enfrentados por estes locais.

\section{CONSIDERAÇÕES FINAIS}

A partir deste estudo foi possível compreender um pouco melhor o papel dos coordenadores das instituições de atendimento destinadas a crianças e adolescentes em situação de rua. Estes profissionais atuam em um campo de trabalho repleto de ambigüidades, que incluem o reforço da situação que pretendem extinguir, o caráter permanente assumido pelos serviços em oposição ao planejado aspecto de transitoriedade, entre outros. Além disto, precisam constantemente lidar com os sentimentos de impotência e onipotência que permeiam as suas atuações e representam uma das grandes dificuldades do trabalho.

É importante ressaltar ainda o alto nível de engajamento dos participantes deste estudo com a questão das crianças e dos adolescentes em situação de rua, corroborando os achados por Câmara e cols. (2002). Pôde-se perceber, ao logo da execução do estudo, a forma passional como a maioria dos respondentes se referiu ao trabalho que desenvolve. O envolvimento com esta população parece ultrapassar a questão profissional e se torna uma militância social, em função da defesa dos direitos destas crianças e adolescentes. Provavelmente este tipo de engajamento seja indispensável para a permanência neste tipo de trabalho, que envolve um nível de frustração tão elevado.

Por fim, é relevante enfatizar a necessidade de cuidados para com estes profissionais que se dedicam tão intensamente ao atendimento de crianças e adolescentes em situação de rua. Tais cuidados possibilitariam um aprimoramento da qualidade dos serviços prestados, possibilitando a esse profissional condições adequadas para o desempenho de suas funções. Para aperfeiçoarem-se, eles precisam não só estar expostos ao trabalho permanente com os jovens, mas em contínua formação pessoal e capacitação profissional acompanhada. Um espaço de discussão e de supervisão sistemática garantiria aos coordenadores e a toda a sua equipe a percepção de que há interesse na sua função e que os cuidadores também estão sendo cuidados. Estes procedimentos garantiriam a eles sentimentos mais fortes, de capacidade de desempenho diante do trabalho e superação de sentimentos de impotência que os levam a sentir como "é difícil tirar a rua do menino".

\section{REFERÊNCIAS}

Alves, P. B. (1998). O brinquedo e as atividades cotidianas de crianças em situação de rua. Dissertação de Mestrado Nãopublicada, Programa de Pós-Graduação em Psicologia do Desenvolvimento, Universidade Federal do Rio Grande do Sul, Porto Alegre.

Alves, P. B. (2002). Infância, tempo, atividades cotidianas de crianças em situação de rua: as contribuições da teoria dos sistemas ecológicos. Tese de Doutorado Não- publicada, Programa de Pós-Graduação em Psicologia do Desenvolvimento, Universidade Federal do Rio Grande do Sul, Porto Alegre.

Alvim, M. R. B. \& Valladares, L. P. (1988). Infância e sociedade no Brasil: uma análise da literatura. BIB: Revista Brasileira de Informação Bibliográfica em Ciências Sociais, 26, 3-37. 
Aneci Rosa, C. S., Borba, R. E. S. R. \& Ebrahim, G. J. (1992). The street children of Recife: A study of their background. Journal of Tropical Pediatrics, 38, 34-40.

Aptekar, L. (1996). Crianças de rua nos países em desenvolvimento: uma revisão de suas condições. Psicologia: Reflexão e Crítica, 9, 153-184.

Bandeira, D. R. (1999). A avaliação de um projeto social do ponto de vista do desenvolvimento psicológico de seus participantes. Tese de Doutorado Não-publicada, Programa de Pós-Graduação em Psicologia do Desenvolvimento. Universidade Federal do Rio Grande do Sul, Porto Alegre.

Bardin, L. (1979). Análise de conteúdo (L. A. Reto \& A. Pinheiro, Trads.). São Paulo: Martins Fontes.

Brasil. (1990). Estatuto da Criança e do Adolescente. Lei n. 8.069, de 13/07/1990. São Paulo: Cortez.

Brito, R. C. (1999). Uso de drogas entre meninos e meninas em situação de rua: subsídios para uma intervenção comunitária. Dissertação de Mestrado Não-publicada, Programa de PósGraduação em Psicologia do Desenvolvimento, Universidade Federal do Rio Grande do Sul, Porto Alegre.

Brito, R. C. \& Koller, S. H. (1999). Desenvolvimento humano e redes de apoio social e afetivo. Em A. M. Carvalho (Org.), $O$ mundo social da criança: natureza e cultura em ação (pp. 115130). São Paulo: Casa do Psicólogo.

Bronfenbrenner, U. (1996). A ecologia do desenvolvimento humano: Experimentos naturais e planejados. Porto Alegre: Artes Médicas. (Originalmente publicado em 1979).

Bronfenbrenner, U. \& Morris, P. (1998). The ecology of developmental processes. In W. Damon (Org.), Handbook of child psychology: Theorical models of human development (pp. 993-1027). New York: John Wiley \& Sons.

Câmara, M. F. B., Moraes, M. M., Medeiros, M. \& Ferriani, M. G. C. (2000). Aspectos da assistência prestada a crianças e adolescentes em situação de rua no município de Goiânia. Revista Eletrônica de Enfermagem, 3(1). Disponível em: http://www.fen.ufg.br/revista. (Acessado em 14/12/2002).

Câmara, M. F. B. Medeiros, M. Ferriani, M.G.C. \& Gomes, R. (2002). O abandono social da infância e adolescência na ótica dos dirigentes de instituições de assistência a crianças e adolescentes em situação de rua na cidade de Goiânia. Revista Brasileira de Crescimento e Desenvolvimento Humano, 12(1), 9-16.

Cecconello, A. M. \& Koller, S. H. (2003). Inserção ecológica na comunidade: uma proposta metodológica para o estudo de famílias em situação de risco. Psicologia: Reflexão e Crítica, 16, 515-524.

Forster, L. M. K., Barros, H. M. T., Tannhauser, S. L. \& Tannhauser, M. (1992). Meninos na rua: relação entre abuso de drogas e atividades ilícitas. Revista da ABP-APAL, 14, 115120 .

Koller, S. H. (1994). Julgamento moral pró-social de meninos e meninas de rua. Tese de Doutorado Não-publicada, Programa de Pós-Graduação em Educação, Pontifícia Universidade Católica do Rio Grande do Sul, Porto Alegre.

Luccinni, R. (2000). A criança da rua: Realidade complexa e discursos redutores. Revista Infância e Juventude, 1, 9-44.

Maciel, C., Brito, S. \& Camino, L. (1997). Caracterização dos meninos em situação de rua de João Pessoa. Psicologia: Reflexão e Crítica, 10, 315-334.

Martins, R. A. (1996). Censo de crianças e adolescentes em situação de rua em São José do Rio Preto. Psicologia: Reflexão e Crítica, 9, 101-122.

Medeiros, M. \& Ferriani, M. G. C. (1995). Programas de atenção às crianças e adolescentes em situação de rua: Percepções de seus dirigentes. Revista Brasileira de Crescimento e Desenvolvimento Humano, 5(1/2), 48-59.

Nunes, T. (1994). O ambiente da criança. Cadernos de Pesquisa, 89, 5-23.

Santana, J. P. (2003). Instituições de atendimento a crianças $e$ adolescentes em situação de rua: objetivos atribuídos por seus dirigentes e pelos jovens atendidos. Dissertação de Mestrado Não-publicada, Programa de Pós-Graduação em Psicologia do Desenvolvimento, Universidade Federal do Rio Grande do Sul, Porto Alegre. .

Santana, J. P., Doninelli, T. M., Frosi, R. V. \& Koller, S. H. (2004). Instituições de atendimento a crianças a adolescentes em situação de rua. Psicologia e Sociedade, 16(2), 59-70.

Santana, J. P., Doninelli, T. M., Frosi, R. V. \& Koller, S. H. (no prelo). Os adolescentes em situação de rua e as instituições de atendimento: utilizações e reconhecimento de objetivos. Psicologia: Reflexão e Crítica.

Santana, J. P. \& Koller, S. H. (2004). As instituições de atendimento e as famílias dos jovens em situação de rua: Funções excludentes ou complementares? Em M. R. F. de Azambuja, M. V. Silveira \& D. D. Bruno (Orgs.), Infância em família: Um compromisso de todos (pp. 129-135). Porto Alegre: IBEDFAM.

Yunes, M. A. M. Arrieche, M. R. O. \& Tavares, M. F. A. (1997). Meninos(as) em situação de rua na cidade de Rio Grande: vida na rua e vida na instituição. Momento, 10, 131142.

Recebido em 04/10/2004 Aceito em 30/05/2005
Endereço para correspondência:
Juliana Prates Santana, Instituto de Psicologia, Rua Ramiro Barcelos, 2600/104, CEP 90035-003, Porto Alegre-RS. E-mail: jps1103@msn.com 